by piles of newsprint and cardboard. This situation had only come about after her daughter had moved from her own accommodation to the patient's two-bedroomed flat. A collateral history from the patient's community medical social worker and general practitioner confirmed the patient's account of enforced domestic squalor for the previous year. The daughter's problem with hoarding of rubbish had been present over 20 years, resulting in a state of such clutter in her own flat as to make it uninhabitable. This had led to her taking up residence with her mother. She had no insight into her hoarding problem, seeing this as reasonable behaviour.

Diogenes syndrome by proxy is a clear example of 'elder abuse', although it may be unintentional as in this, the first described case. The aetiology in this case is unknown, as the patient's daughter has never had a formal psychiatric evaluation. Diogenes syndrome is usually encountered in persons over 60 years (Macmillan \& Shaw, 1966; Clark et al, 1975), but it is recognised in younger patients in association with chronic alcoholism, chronic paranoid schizophrenia, and major affective disorder (Berlyne, 1975). The problem may be insidious, escaping recognition and being incorrectly ascribed to eccentric behaviour or senile dementia in an elderly person. Absence of physical injury may obscure the diagnosis of Diogenes syndrome by proxy. As in the case of Munchausen syndrome by proxy, very young or elderly dependants of patients with documented or suspected Diogenes syndrome must be considered at risk of Diogenes syndrome by proxy, even when the patient lives alone, which is the case with most patients with Diogenes syndrome (Cybulska \& Rucinski, 1986).

BERLYNe, N. (1975) Diogenes syndrome. Lancet, $i, 515$.

Clark, A.N.G., Mankikar, G.D. \& Gray, I. (1975) Diogenes syndrome. A clinical study of gross neglect in old age. Lancet, $i$. 366-368.

CYbulska, E. \& Rucinski, J. (1986) Gross self-neglect in old age British Journal of Hospital Medicine, 36, 21-25.

Macmillan, D. \& Shaw, P. (1966) Senile breakdown in standards of personal and environmental cleanliness. British Medical Journal, ii, 1032-1037.

Denis O'MAHONY J. Grimley Evans

Department of Clinical Geratology

Radcliffe Infirmary

Woodstock $R d$

Oxford $O X 26 H E$

\section{How abuse has affected me}

$A$ is now 22 years old and has received at least four periods of in-patient treatment, having been on an acute ward for the last year. She is a self-mutilator who has a long history of sexual abuse.
She has not been able to confide in male members of staff but did, with encouragement, take a BTech course. As part of that course she submitted a dissertation on her abuse, obtaining a distinction for her work.

As our therapeutic partnership progressed, she was eventually able to let me read this dissertation, and I was particularly intrigued by the passage which is given below. I find it poignant and thought provoking and, with A's permission, am happy to share her observations with you.

I make no comment as to the content and meaning of her words, and hope that you will be able to gain as much insight from her observations as I have.

"My name is [A] and I am twenty two years old. I suffered physical and sexual abuse from the age of three until I left home at seventeen years of age.

\section{How ABUSE has affected ME}

"I am ANGRY with myself / I do not like being looked at / I don't trust myself or others - men / I BLAME MYSELF / I feel DIRTY and GUILTY / I am a perfectionist / I am afraid of bathing and swimming / I feel paranoid / I have poor self respect / I am self conscious / I feel INFERIOR / I am SCARED of relationships / I am scared of being touched / I feel UNWORTHY / I don't like silence / I have agoraphobia / I feel WITHDRAWN / I am overprotective - of children / I don't like wearing clothes in case they get dirty / I don't wear skirts, only trousers / I wear dark clothes / I am AFRAID to be alone with a man / I feel I should HARM myself / I like to be poorly - for attention / I don't feel creative / I am highly strung / I feel edgy / I am DEFENSIVE/I lack self-confidence $/$ I have NIGHTMARES and flashbacks / I hear voices / I have hallucinations / I find situations DANGEROUS / I have amnesia.

Stanley Royd Hospital Wakefield

STEPhEN H. ShaW

\section{Estimates of risks in relatives of psychotic probands}

SIR: There is compelling evidence that genetic factors are important in determining susceptibility to schizophrenia (Gottesman, 1990). Knowledge of the lifetime risks of schizophrenia in the general population and in various classes of relatives of 
schizophrenic probands is important for genetic counselling, and also provides insights into the mode of transmission of the disorder. Risch (1990) used such data to conclude that at least two genes whose effects interact are involved in predisposing to schizophrenia.

Estimates of the lifetime prevalence of schizophrenia in the general population and in first-degree relatives of schizophrenic probands are available from several investigations using direct interview of subjects, often supplemented by case-note information. In contrast, such estimates for second- and third-degree relatives come from family history studies, in which information is gathered mainly from an informant rather than directly from the subject. Although we do not yet have a psychiatric diagnostic 'gold standard', family history methods are generally inferior to direct interview methods, and in studies of affective disorder may underestimate the rate of affective illness by as much as $85 \%$ in first-degree relatives of informants (Gershon \& Guroff, 1984). The degree of underestimation almost certainly increases greatly with more distant relatives (Giuffra, 1991).

In psychiatry we use operational definitions for the disorders we study. Bridgman (1927) introduced operational thinking into physics because he recognised that the operations used to measure an entity themselves define the entity under investigation. Changing the measurement operation changes the entity being measured. Because lifetime risks of schizophrenia in first-degree and in more distant relatives of schizophrenic probands have not been measured using the same methods, the results are not directly comparable.

We urge caution in the use of estimates of lifetime risk of psychotic disorders in second- and third-degree relatives of schizophrenic probands. Good data are not available. Current estimates suggest a small increase of risk above that in the general population for second-degree relatives (Gottesman, 1990). The qualitative finding of an increase should be robust. However, the magnitude of the increase is not known, and may be significantly higher than the values quoted in textbooks. The true risk to third-degree relatives of schizophrenic probands is even less well known.

Bridgman, P.W. (1927) The Logic of Modern Physics. New York: MacMillan.

GERSHON, E.S. \& GUROFF, J.J. (1984) Information from relatives. diagnosis of affective disorders. Archives of General Psychiatry, 41, 173-180.

GuUfrA, L.A. (1991) Genetic Analysis of Complex Traits. PhD thesis, Yale University.
Gotresman, I.I. (1990) Schizophrenia Genesis: The Origins of Madness. New York: Freeman.

RiscH, N. (1990) Linking strategies for genetically complex traits. I Multilocus models. American Journal of Human Genetics, 46, 222-228.

Nick Craddock

LuIS A. GIUFFRA

Department of Psychiatry

School of Medicine

Washington University in St Louis

USA

\section{Childhood sexual abuse and mental health}

SIR: We have researched the long-term consequences of childhood sexual victimisation and family background in a non-clinical sample of female students. Our findings (Kinzl et al, 1994) confirm and supplement those of Mullen et al (BJP, December 1993, 163, 721-732).

Our data suggest that both family dysfunction and sexual victimisation contribute to sexual disorders in adulthood. Women who experienced multiple sexual abuse often reported intimacy disturbances and impairment of sexual pleasure. Despite a negative attitude towards men and sexuality, many lived in a sexual relationship without enjoying it. Female orgasm was the most susceptible part of the sexual response cycle in women with a history of CSA.

Our results also indicate that the eating disorder frequently observed in sexually abused women is due less to sexual victimisation per se than to a dysfunctional family background. CSA is neither necessary nor sufficient for the development of a personality or neurotic disorder; however, it may be an important aetiological factor because of its effects on personality and emotional development (e.g., low sense of self-worth, feelings of shame and guilt, disgust, unwillingness to trust, and a sense of personal failure).

It may be said that, over time, the abuse-related factors are less influential than the continuing family processes, such as the quality and amount of family support for the child.

KinzL, J.F., Trawecer, C. \& Brebl, W. (1994) Sexual dysfunction: relationship to childhood sexual abuse and early family experiences in an nonclinical sample. Child Abuse and Neglect (in press).

JoHANN F. KINZL WIIFRIED BIEBL

Univ.-Klinik für Psychiatrie Innsbruck

A-6020 Innsbruck

Austria 